\title{
Ölçeklerin Yapı Geçerliğini Belirlemede Bir Yöntem Olarak Yapay Sinir Ăğı Modelinin İncelenmesi: Kendini Düzenleyen Haritalama
}

\author{
Investigation On Artificial Neural Network Model As A Method \\ In Determining Construct Validity Of Scales: Self-Organizing \\ Mapping
}

\author{
Esin TEZBAŞARAN *
}

\begin{abstract}
$\ddot{O} \mathbf{z}$
$\mathrm{Bu}$ araştırmada, yapay sinir ağı modellerinden biri olan kendini düzenleyen haritalama yönteminde kullanılan nöron sayısının, ölçeklerin yapılarını ortaya çıkarmadaki etkililiği incelenmektedir. Bu yöntemde haritalama yaparken kullanılan nöron sayısı değiştikçe, ölçek yapısı farklılaşabilmektedir. Bu çalışmada ölçek yapısını ortaya çıkarmada en uygun nöron sayısının tespiti için kullanılan yöntemler doğrulayıcı faktör analizi ve farklı gruplar yöntemidir. Araştırma bulguları, nöron sayısı arttıkça ölçek yapısının tek faktöre indirgendiği aynı zamanda, tek faktörde ortaya çıkan bu ölçeğin uyum ve hata indeksleri açısından diğerlerine göre daha uyumlu bir model meydana getirdiğini ortaya çıkarmıştır. Bunun yanı sıra farklı gruplar yönteminden elde edilen kanıt da bu durumu desteklemektedir. Sonuç olarak, yapı geçerliği için kullanılan kendini düzenleyen haritalama yönteminde, ölçeğin ilişkili maddeleri tek nöronda toplanıncaya kadar nöron sayısının artııılması önerilmektedir. Buna ek olarak, ortaya çıkan yapının bağlamsal olarak ölçülen tutum değişkeni açısından analiz edilmesi de önerilmektedir.
\end{abstract}

Anahtar Kelimeler: Yapı geçerliği, kendini düzenleyen haritalama

\begin{abstract}
This research investigates the efficiency of number of neurons used in self-organizing mapping, one of the artificial neural network models, on detecting construct of scales. In this method, the construct of a scale can differ as the number of neurons used for mapping changes. In this study, the methods for determining the optimum number of neurons to detect the construct of a scale are confirmatory factor analysis and distinct groups method. The research findings reveal that increasing neuron numbers causes reduction through one factor of the scale construct and, at the same time, the fit and error indexes of this scale constructed in one factor have more fitted model than those of others. In addition to this, the evidence from distinct groups method supports this finding. As a result, it is recommended that the number of neurons should increase till the related items of a scale are gathered in a neuron in the method of self-organizing mapping used for construct validity. In addition to this rule, it is recommended to analyze the revealed construct with respect to related attitude variable contextually.
\end{abstract}

Keywords: Construct validity, self-organizing mapping

\section{GíRiş}

Yapı geçerliği psikolojik değişkenleri ölçme amacıyla geliştirilen araçlar için geçerlik kanıtı olabilecek önemli bir psikometrik özelliktir. Yap1 geçerliği, psikolojik bir yapıy1 ya da özelliği, ölçme aracının ne derecede ortaya koyabildiği ile ilgilidir (Anastasi, 1988). Bir ölçme aracının maddeleri, yapının değerlendirilmesine dönük bir araçlar takımıdır. Çünkü, değişkene ait yapı doğrudan gözlenemez (De Vellis, 2003). O halde soyut olan psikolojik yapı ile gözlenebilir, somut davranışların ilişkisini ortaya koyma durumu, yapı geçerliğini belirlemede temel anahtardır (Murphy ve Davidshofer, 2001).

\footnotetext{
* Dr., İstanbul Üniversitesi, Hasan Ali Yücel Eğitim Fakültesi, İstanbul-Türkiye, tezbasaranesin@gmail.com 
Bir ölçme aracının yapı geçerliği, farklı yöntemlerle kanıtlar elde edilerek ve bu kanıtlar değerlendirilerek saptanır. $\mathrm{Bu}$ yöntemlerden birisi, özellikle Likert tipi ölçek geliştirme uygulamalarında, temel bileşenler analizi tekniği kullanarak, ölçme aracının boyutlarını ortaya koyan faktör analizi yöntemidir.

Temel bileşenler analizinin genel amacı, veri azaltma ve veriyi yorumlamadır (Johnson ve Wichern, 1982). Bu analiz doğrusal bir analiz tekniği olması nedeni ile doğrusal olmayan ilişkileri ortaya çıkarmada yetersizdir. Ayrıca bu analizin kullanılabilmesi için değişkenlerin sürekli olması ve normallik sayıltılarının karşılanması gerekir. 1943 yılından itibaren yapay sinir ağı modellerinin gelişmesi ile bu modellerin veri analizlerinde kullanım alanları da genişlemiş ve birçok parametrik yöntemler için gerekli olan sayıltılara gerek duymayan yapay sinir ağı modelleri kullanımı yaygınlaşmıştır. Artık birçok istatistiksel yöntemler, yapay sinir ağları üzerinden modellenebilmektedir (Cheng ve Titterington, 1994). Literatürde, Kohonen ağ olarak da bilinen Kendini Düzenleyen Haritalama $(\mathrm{KDH})$ modelinin ise teori ve uygulamada, faktör analizi yerine kullanılabildiğini gösteren çalışmalar mevcuttur. Özellikle Kohonen (2013), KDH'nın istatistiksel yöntemlerden açımlayıcı veri analizi yerine kullanılabileceğini belirtir.

Kohonen (1982), kendini düzenleyen bir haritalama yapan ağın temel prensibinin, gözlenen olayların özelliklerine göre geometrik düzlemde gerçeğe uygun haritalarını otomatik olarak düzenlemesi olarak tanımlar. KDH, dış dünyadan gelen sinyallere göre girdi özelliklerinin haritasını çıkaran bir ağ modelidir. Bu özelliği nedeni ile $\mathrm{KDH}$, çok boyutlu bir yapıya sahip olan veri setinin boyut sayısını indirgeyerek, iki boyutlu bir haritada görselleştirir. Bu ağ, çok boyutlu girdi sinyallerini işleyerek, iki boyutlu düzlemde soyut bilgiyi ortaya koyabilen bir yapay sinir ağı yapısıdır (Kohonen,1990).

KDH tek katmanlı mimari yapıda, ileri beslemeli, denetimsiz öğrenme yöntemine sahip bir ağ modelidir (Şekil 1). KDH için kullanılan öğrenme yöntemi, denetimsiz öğrenme yöntemidir; beklenen bir çıktı değeri yoktur. O yüzden ölçüt, girdilerin benzerlik ya da farklılıkları üzerinden belirlenir ve çıktı katmanında ağın tespit ettiği benzerliklere göre kümeler oluşur. Bunun için her bir nöron, girdi vektörü ile ağırlık vektörü arasında oklit uzaklığını hesaplar.

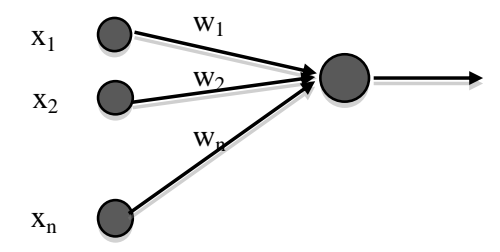

Girdi katmanı Çıktı katmanı

Şekil 1. Tek Katmanlı İleri Beslemeli Yapay Sinir Ağı Mimarisi

$\mathrm{KDH}$, yarışmacı öğrenme kuralı kullanır. Yarışmacı öğrenme kuralı kullanan ağ yapısı ile, girdilerin özelliklerini göz önüne alarak kümelemesi, KDN'nın temel işlevidir. Buna göre algoritmada eğitim girdi vektörlerinin $\left(x_{i}(t)\right), c$ kümelerine sinıflandırılması için ağırlık güncellemesini $\left(w_{C}(t+1)\right)$ koşullu olarak formüllendirilir. $\propto(t)$, her adımda monoton olarak azalan skaler bir değerdir. Genellikle $\propto(t)$ için 0,01 ya da 0,02 başlangıç değeridir.

$$
\begin{aligned}
& w_{C}(t+1)=w_{C}(t)+\propto(t)\left[x_{i}(t)-w_{C}(t)\right] \text { Ĕ̆er } x \text { doğru sinıflandirllmış ise, } \\
& w_{C}(t+1)=w_{C}(t)-\propto(t)\left[x_{i}(t)-w_{C}(t)\right] \text { Ĕger } x \text { yanlış sınıflandırılmış ise, } \\
& w_{i}(t+1)=w_{i}(t) \quad \text { Ĕger } i \neq c
\end{aligned}
$$


KDH veri hazırlama, modelleme ve kümeleme amacıyla kullanılabilmesinin yanında, bilginin keşfedilmesi sürecinde veriyi anlama açısından da oldukça uygun bir yöntemdir (Vesanto, Himberg, Alhoniemi ve Parhankangas, 2000). KDH ile veriler (girdiler) üzerinden soyut bilginin ortaya çıkarılması ve yapı geçerliği arasında önemli bir örtüşme olduğu düşüncesiyle, denemelik ölçeklerin yapı geçerliği için KDH kullanımının incelenmesi önemlidir.

\section{Araştırmanın Amacı}

KDH modeli için bir takım desen parametreleri vardır: Nöron serisinin boyutluluğu, her bir boyuttaki nöron sayısı, nöronların birbiri ile komşuluk ilişkisi/şekli, komşuluğun yakınlaşma planı ve ağın öğrenme hızı (Jain, Mao ve Mohiuddin, 1996). KDH sonuçlarını etkileyen parametreler içinde, modelde önceden belirlenen nöron sayısı, çıktı haritasıyla ortaya çıkan bilgiyi değiştirebilmektedir. $\mathrm{Bu}$ değişkenlik, ölçeklerin yapısı hakkında elde edilen bilginin de değişmesi anlamına gelmektedir. $\mathrm{Bu}$ düşünceden yola çıkarak bu araştırmada, çıktı haritasında bulunan nöronların sayılarındaki artış ya da azalışın, bir ölçeğin yapı geçerliği çalışmasına nasıl yansıyacağına ve yapı geçerliği çalışmasında en uygun nöron sayısının ne olacağına yönelik KDH modelinin incelenmesi amaçlanmiştır.

$\mathrm{Bu}$ amaçla tasarlanan araştırmada, yapay sinir ağı modellerinden biri olan KDH modelinde farklı nöron sayıları üzerinden yapılan haritalamada, Tezbaşaran ve Kelecioğlu (2004) tarafından hazırlanan denemelik Sigaraya İlişkin Tutum Ölçeğinin yapı geçerliği saptamada en uygun nöron sayısını tespit edebilmek için aşağıdaki sorulara cevap aranmaktadır:

1. Farklı nöron sayıları üzerinden uygulanan KDH yöntemi sonuçlarına göre ölçek yapısı nasıldır?

2. KDH yönteminde değişen nöron sayıları sonucunda ortaya çıkan ölçek yapılarının doğrulayıcı faktör analizi sonuçlarına göre uyum ve hata indeksleri nedir?

3. KDH yönteminde değişen nöron sayıları sonucunda ortaya çıkan ölçek yapılarının farklı gruplardan elde edilen kanıtlara göre yapı geçerliği nasıldır?

\section{Sinırlılıklar}

$\mathrm{Bu}$ araştırmanın sonuçları yalnızca katılımcılardan elde edilen verilerle sınırlıdır, genelleme yapılamaz. Ayrıca, cinsiyet ve sigara kullanımı açısından araştırma grubunun frekans dağılımları arasındaki açıklık araştırma sonuçları açısından önemli bir sınırlılıktır. Bunun yanı sıra, KDH'da kullanılan ağın başlangıç ağırlık değerleri ve girdi sırası her seferinde rasgele atandığından dolayı, $\mathrm{KDH}$ analizinin verdiği sonuçlar tekrarda aynı olmayabilir.

\section{YÖNTEM}

\section{Araştırmanın Türü}

$\mathrm{Bu}$ araştırma, KDH modeli kullanan yapay sinir ağı modelinin ölçeklerin yapı geçerliğine kanıt oluşturmak üzere en uygun nöron sayısının tespitine yönelik olduğundan, temel araştırmadır. Temel araştırmalar, var olan bilgiye yenilerini katan araştırmalardır (Karasar, 1998). Bu araştırmalar tarafından üretilen bilgiler pratikte hemen uygulanabilir bilgiler değildir ancak, uygulamaya dönük çalışmalar için gerekli bilgi kaynağını ya da altyapısını oluştururlar (Elmes, Kantowitz ve Roediger III, 1992; Bogden ve Biklen, 1998).

\section{Çalışma Grubu}

$\mathrm{Bu}$ araştırmaya üniversitede okuyan ya da mezun olmuş 18-56 yaş grubundaki 540 birey, gönüllü olarak katılımcı olmuşlardır. Sigaraya İlişkin Tutum Ölçeğinin uygulandığı grubun \%83,5’i kadın, 
\%16,5 'i erkektir. Kadınların \%15'i, erkeklerin ise \%75'i sigara kullandığını belirtmişlerdir. Bireylerin \%59,6'sı üniversite öğrencisi, \%40,4'ü ise üniversite mezunu olup; katılımcılar 48 farklı meslek gruplarına ait bölümlere dağılım göstermektedir.

\section{Veri Toplama Aracı}

Veri toplama aracı iki bölümden oluşmaktadır. Birincisi demografik bilgilerin alındığı ve sigaraya ilişkin sorulardan oluşan anket ve Tezbaşaran ve Kelecioğlu (2004) tarafindan hazırlanan Sigaraya İlişkin Tutum Ölçeğidir. 41 maddeden oluşan denemelik ölçek 5'li Likert tipinde bir ölçek olup, 19 maddesi olumlu, 22 maddesi olumsuz ifadelerden oluşmaktadır. Orjinal çalışmada, ölçeğin güvenirliğinin 1322 kişi üzerinden yapılan uygulama ile 0,92 olduğu ve açımlayıcı faktör analizi sonucu ölçekte iki bileşen gözlendiği belirtilmektedir. Birinci bileşenin açıkladığı varyans \%25,41, ikinci bileşenin açıkladığı varyans ise \%7,25’dir (Tezbaşaran ve Kelecioğlu 2004).

\section{Verilerin Analizi}

Öncelikle Sigaraya İlişkin Tutum Ölçeğindeki sigaraya ilişkin olumsuz maddeler tersten puanlanarak, yüksek puanların olumlu tutum, düşük puanların olumsuz tutumu ifade edecek şekilde düzenlemesi yapılmıştır. Araştırmanın birinci alt problemini cevaplamak üzere, ölçek üzerinden elde edilen veriler girdi değerleri olarak, yapay sinir ağ modeli olan KDH yazılımının bulunduğu MatlabSOM toolbox programında farklı nöron sayıları üzerinden uygulanmış; ölçeğin yapısı faktörler ve bu faktörleri oluşturan maddeler üzerinden belirlenmiştir. Sonuçlar vuruş (hit) histogramı üzerinden görselleştirilmiştir. Bu çizim verinin haritadaki dağılımını görmek açısından iyi bir araçtır (Westerlund, 2005). Aynı zamanda yazılıma, nöronlarda toplanan maddelerin hangileri olduğunu tanımlayacak bir kod eklenmiştir. Yazılımda kullanılan iterasyon sayısı 500 olarak belirlenmiştir. Ağın çıktısı sırasıyla 2x2, 3x3, 4x4, 5x5, 6x6, 7x7 nöron haritası üzerinden elde edilmiştir. KDH iki boyut üzerinden haritalandırma yapar ve bu araştırma için her bir boyuttaki nöron sayısı $n$ olmak üzere, $n x n$ boyutunda, altıgen 1zgara yapısında görüntüleme kullanılmıştır.

Araştırmanın ikinci alt problemi için 6 farklı haritalamadan çıkan ölçek yapıları doğrulayıcı faktör analizine tabi tutulmuştur. DFA, denence olarak ortaya konan yapının veri seti ile iyi bir uyum gösterip göstermediğini belirler (Holtzman ve Vezzu, 2011). Bu amaçla, Lisrel 9.2 programı ile yapılan doğrulayıcı faktör analizi sonuçlarında ortaya çıkan her bir yapının uyum ve hata indeksleri belirlenmiştir.

Ayrıca üçüncü alt problemde nöron sayılarına göre farklılaşan ölçek yapılarının yapı geçerliği açısından kuvvetli olanı tespit için, diğer bir yapı geçerliği belirleme yöntemi olan farklı gruplar yöntemi kullanılmıştır. Eğer bir ölçme aracı istenen yapıyı geçerli bir biçimde ölçüyor ise, bu yapıya ilişkin farklı olduğu bilinen grupları, ölçüm sonucu üzerinden ayırabilmelidir. (Cohen, Montague, Nathanson ve Swerdlik, 1988). Bu amaçla farklı gruplar sigara içenler ve içmeyenler olarak belirlenmiştir. Çünkü Feldman (1997), davranışlar ve tutumlar arasındaki bağın kuvveti değişmekle birlikte, genel olarak insanların tutum ve davranışları arasında bir tutarlılık sağlamak için çaba gösterdiklerini belirtir. Buna göre, 6 farklı ölçek yapısına ait puanlar üzerinden, iki grup arasındaki puan ortalamaları farkının manidarlığı, bağımsız gruplar için t testi ile SPSS 21.0 programı kullanılarak test edilmiştir. Ancak araştırma grubunun sigara kullananların sayıs1 (90) ile kullanmayanların sayısı (450) arasında yüzde olarak büyük açıklık vardır (yaklaşık \%66,7). Bu nedenle analiz, sigara kullanmayanlar arasından rasgele yöntemle seçilen 90 kişilik grup belirlenerek yapılmıştır.

\section{BULGULAR}

Bulgular, araştırmada belirlenen problemlerin sırasına göre birer başlık altında verilmiştir. 


\section{Farklı Nöron Sayılarında Haritalanan Ölçek Yapıları}

Başlangıç KDH için 2x2 üzerinden 4 adet nöron kullanılmıştır. Bunun nedeni tek nöron üzerinde ölçeğin tüm maddelerinin görüntülenecek olmasıdır. İki boyutlu haritalamada, Sigaraya İlişkin Tutum Ölçeğinin maddeleri 4 nörona dağılmıştır. Ölçekteki 2. madde diğerlerinden ayrılarak dördüncü nöronda olmak üzere, ilk nöronda 9 madde, ikincisinde 22 ve üçüncüsünde 9 madde bulunmaktadır (Şekil 2-a). Buna göre 2. maddenin bulunduğu nöron dışta tutulmak kaydı ile ölçek yapısının üç faktörlü olduğu söylenebilir (Tablo 1).

İki boyutlu haritalamada nöron sayısı $3 \times 3$ olmak üzere 9 olarak belirlendiğinde ortaya yine üç faktörlü bir yapı ortaya çıkmıştır. Nöronların birincisinde 8 , üçüncüsünde 19 ve yedincisinde ise 8 madde toplanmıştır. Kalan nöronlar diğer 6 maddeyi paylaşmıştır (Şekil 2-b).

Nöron sayısı 4x4 üzerinden 16'ya çıkarıldığında beşinci nöronda 8, on altıncı nöronda 18 madde görülmektedir. Böylelikle faktör sayısının ikiye düştüğü gözlenmiştir (Şekil2-c). Nöron sayısı 5x5 üzerinden 25 olduğunda, maddeler farklılıklarına ve benzerliklerine göre daha da ayrışarak altıncı nöronda 3, onuncu nöronda 14 madde, on yedinci nöronda 2 madde ile faktör yapısı tekrar üç olmaktadır (Şekil2-ç). Ancak bir faktörde 2 maddenin bulunması istenmeyen bir durumdur. Kline (2005), özellikle örnek sayısı küçük ise faktör başına en az üç değişkenin bulunmasını önerir.

Haritadaki toplam nöron sayısı 36'ya çıktığında, 5x5'lik haritadaki maddelerin de birbirinden ayrıştı̆̆ 1 ancak, 3 maddelik faktöründe ayrışarak ikiye düştüğü ve birinci nöronda iki maddenin kaldığı görülmektedir (Tablo 1). Birincil faktör olarak 9 maddelik bir yapı ortaya çıkmıştır (Şekil 2d). Maddelerin ayrışmasını boyuttaki nöron sayısını bir artırarak 7x7'lik harita üzerinden incelendiğinde (Şekil 2-e), 5 maddelik tek boyutlu bir yapının ortaya çıktığg görülmektedir. Bunun üzerine nöron artışı durdurulmuştur. Çünkü nöron sayısı arttırıldığında maddelerin her biri bir nöronda olmak üzere dağılmıştır.

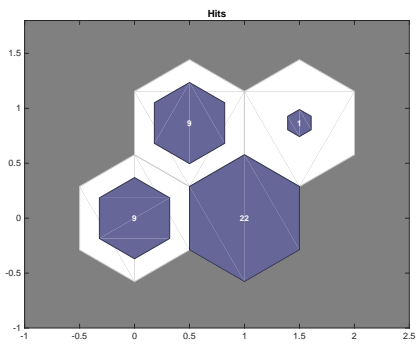

(a)

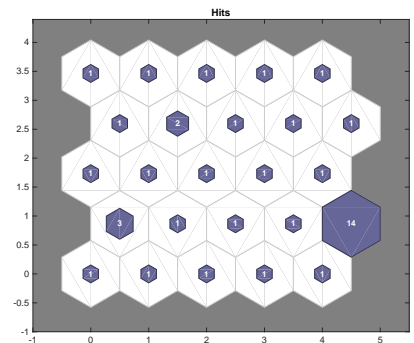

(ç)

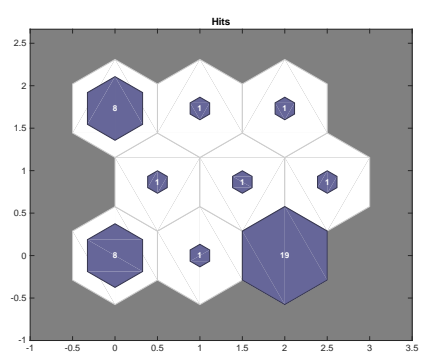

(b)

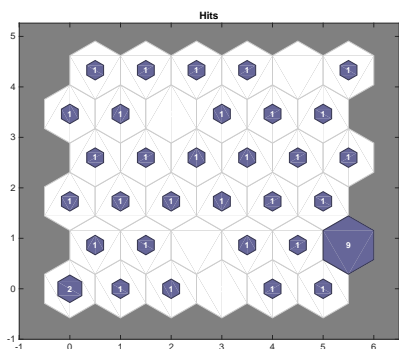

(d)

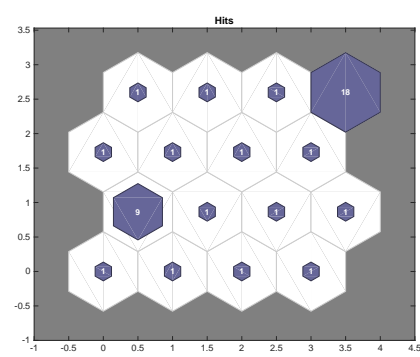

(c)

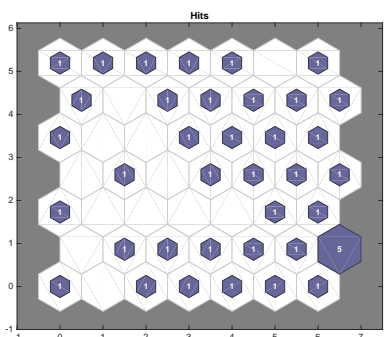

(e)

Şekil 2. KDH Sonucu Maddelerin Nöronlara Dağılımını Gösteren Vuruş Histogramı: a) 2x2 b) 3x3 c) $4 \times 4$ ç) $5 \times 5$ d) $6 \times 6$ e) $7 \times 7$ 
Tablo 1. Farklı Nöron Sayılarında KDH Sonuçlarına Göre Maddelerin Faktörlere Dağılımı

\begin{tabular}{|c|c|c|c|}
\hline \multirow[t]{2}{*}{ Norön Sayıs1 } & \multicolumn{3}{|c|}{ Faktörler* } \\
\hline & 1. Faktör & 2. Faktör & 3. Faktör \\
\hline $2 \times 2$ & $\begin{array}{l}6,13,18,19,27,31,32,38 \\
41\end{array}$ & $\begin{array}{l}1,3,5,7,8,9,10,12,15, \\
16,21,23,24,25,28,29, \\
30,33,34,37,39,40\end{array}$ & $\begin{array}{l}4,11,14,17,20, \\
22,26,35,36\end{array}$ \\
\hline $3 \times 3$ & $6,13,18,19,27,31,32,41$ & $\begin{array}{l}1,5,7,8,9,10,12,15,21, \\
23,24,25,28,29,30,33, \\
34,37,39\end{array}$ & $\begin{array}{l}4,11,14,17,20, \\
22,35,36\end{array}$ \\
\hline $4 \times 4$ & $4,13,14,17,20,26,36,38$ & $\begin{array}{l}1,2,3,5,8,15,21,23,24, \\
28,29,30,32,33,34,37, \\
39,40\end{array}$ & \\
\hline $5 \times 5$ & $14,35,36$ & $\begin{array}{l}1,5,9,10,15,21,23,24 \\
28,30,32,33,37,39\end{array}$ & 11,17 \\
\hline $6 \times 6$ & 35,36 & $1,3,5,8,21,23,24,34,39$ & \\
\hline $7 \times 7$ & $1,5,7,21,23^{* *}$ & & \\
\hline
\end{tabular}

*Faktör numaraları nöron numaralarının sıralamasına göre verilmiştir.

** Önceki Nöron sayılarına göre KDH sonuçlarında 2. Faktör içinde yer alan maddelerdir.

\section{Ölçek Yapılarının Uyum ve Hata İndeksleri}

Farklı nöron sayıları üzerinden yapılan $\mathrm{KDH}$ analizinde, Sigaraya İlişkin Tutum Ölçeğinin yapısında, farklı madde ve faktör sayısı olduğu gözlenmiştir. Bu durumda hangi yapının kabul edilebilir olduğunu tespit etmek için doğrulayıcı faktör analizi yapılarak elde edilen uyum ve hata indekslerinden yararlanılmıştır.

İlk olarak $X_{M}^{2}$ uyum istatistiğinin serbestlik derecesine bölümü üzerinden elde edilen uyum indeksine göre hepsi kabul edilebilir uyuma sahip olmakla birlikte 7x7'lik KDH sonucunda oluşan 5 maddeden oluşan tek faktörlü yapı en iyi uyumu vermektedir. Ancak Ullman (2001), bu oranın model uyumu için kaba bir gösterge olduğunu belirtir.

İkinci olarak RMSEA hata indeksi ele alındığında, Hesaplanan değerin 0,05'den küçük olması beklenir ancak, 0,05-0,08 arasındaki değerle de kabul edilebilir bir uyumu sergiler (Kline, 2005). Buna göre hepsi kabul edilebilir sınırlar içinde olmakla birlikte 7x7'lik KDH sonucu en düşük hata indeksine sahiptir.

GFI ve AGFI değerlerinin kabul edilebilir sınırları 0,90 ve yukarısıdır (Kline, 2005). Buna göre 6x6 ve 7x7Lik KDH sonuçlarında oluşan yapılar kabul edilebilir düzeydedir. NFI, NNFI ve CFI uyum indeksleri de 0,90 ve yukarısı değerleri iyi bir uyum indeks değeri olarak kabul edilir (Kline, 2005). Buna göre ölçek yapılarının hepsi kabul edilebilir düzeydir. Ancak KDH analizinde, nöron sayıs1 arttıkça, ortaya çıkan daha az sayıda madde ve faktör sayısı üzerinden oluşan yapıların uyum indekslerinin arttığı gözlenmektedir (Tablo 2).

Tablo 2. Farklı Nöron Sayılarında KDH Sonuçlarına Göre SİTÖ yapısının DFA Uyum ve Hata İndeksleri

\begin{tabular}{lcccccc}
\hline $\begin{array}{l}\text { Uyum ve Hata } \\
\text { Indeksleri }\end{array}$ & $\mathbf{2 x 2}$ & $\mathbf{3 x 3}$ & $\mathbf{4 x 4}$ & $\mathbf{5 x 5}$ & $\mathbf{6 x 6}$ & $\mathbf{7 x 7}$ \\
\hline$X_{M}{ }^{2} / s d$ & $1998,79 / 732=$ & $1432,75 / 524=$ & $806,96 / 298=$ & $438,09 / 149=$ & $102,03 / 43=$ & $9,62 / 5=$ \\
& 2,73 & 2,73 & 2,71 & 2,94 & 2,37 & 1,92 \\
RMSEA & 0,065 & 0,063 & 0,061 & 0,063 & 0,050 & 0,042 \\
GFI & 0,82 & 0,85 & 0,89 & 0,92 & 0,97 & 0,99 \\
AGFI & 0,79 & 0,83 & 0,87 & 0,89 & 0,95 & 0,98 \\
NFI & 0,92 & 0,92 & 0,92 & 0,93 & 0,94 & 0,96 \\
NNFI & 0,94 & 0,94 & 0,95 & 0,95 & 0,96 & 0,96 \\
CFI & 0,95 & 0,95 & 0,95 & 0,95 & 0,97 & 0,98 \\
\hline
\end{tabular}




\section{Ölçek Yapılarının Farklı Gruplar Üzerinden İncelenmesi}

Nöron sayılarına göre KDH'dan elde edilen farklı ölçek yapıları, sigara içenler ve içmeyenler olarak belirlenen iki farklı grubun, altı farklı ölçek puanlarının ortalamaları bağımsız gruplar için t testi ile karşılaştırılmıştır. Yapılan karşılaştırmada farklı nöron sayılarındaki KDH sonuçlarına göre ölçek yapılarının tümünde, sigara kullanan ve kullanmayanların ölçek puanlarının ortalamaları arasındaki farklılığın istatistiksel olarak anlamlı olduğu görülmektedir (Tablo 3). Yalnızca 6x6 ve 7x7'lik nöron haritasına göre çıkan ölçek yapılarından elde edilen grup varyansları homojenliği, Levene testi sonucu reddedilmiştir $(\mathrm{p}<0,05)$. Nöron sayılarındaki değişim nedeni ile, KDH analizi sonucu ortaya çıkan 6 farklı ölçek yapısında, sigara kullananların sigaraya ilişkin tutum puanları ortalamaları yüksek ve kullanmayanların ise düşük olduğu görülmektedir.

Tablo 3. Farklı Ölçek Yapıları Açısından Sigara Kullanım Durumlarına Göre Ölçek Puanları İstatistikleri

\begin{tabular}{llllllll}
\hline Ölçek Yapıları & $\begin{array}{l}\text { Sigara } \\
\text { Kullanımı }\end{array}$ & $\mathrm{N}$ & $\overline{\mathbf{x}}$ & Ss & Sd & $\begin{array}{l}\text { Ortalama } \\
\text { Fark }\end{array}$ & $\mathrm{t}$ \\
\hline $2 \times 2$ & Evet & 90 & 104,60 & 18,00 & 178 & 28,51 & $11,391^{*}$ \\
& Hayır & 90 & 76,01 & 15,59 & & & \\
$3 \times 3$ & Evet & 90 & 90,72 & 15,63 & 178 & 24,32 & $11,244^{*}$ \\
& Hayır & 90 & 66,40 & 13,30 & & & \\
$4 \times 4$ & Evet & 90 & 65,09 & 12,34 & 178 & 17,68 & $10,327^{*}$ \\
$5 \times 5$ & Hayır & 90 & 47,41 & 10,55 & & & \\
& Evet & 90 & 47,52 & 9,06 & 178 & 13,16 & $10,364^{*}$ \\
$6 \times 6$ & Hayır & 90 & 34,37 & 7,93 & & & \\
& Evet & 90 & 25,18 & 5,47 & 168,98 & 6,79 & $9,237^{*}$ \\
$7 \times 7$ & Hayır & 90 & 18,39 & 4,32 & & & \\
& Evet & 90 & 8,58 & 2,50 & 165,52 & 1,78 & $5,387^{*}$ \\
& Hayır & 90 & 6,80 & 1,86 & & & \\
\hline
\end{tabular}

${ }^{*} \mathrm{p}<0,05$

\section{SONUÇLAR ve TARTIŞMA}

Yapay sinir ağı üzerinden KDH analizi sonuçları incelendiğinde, nöron sayısı arttıkça faktörlerde yer alan madde sayısı azalmakta, aynı zamanda son olarak faktör sayısı 1'e düşmektedir. Eğer 2 maddeden bir boyut oluşturan faktörler dışta tutularak KDH sonuçları incelenirse 5x5'lik KDH sonucunun 2 faktörlü, 6x6'lik KDH sonucunun ise tek faktörlü olduğu söylenebilir. Bunun yanı sıra $7 \times 7$ 'lik haritada 5 maddeli tek faktörlü bir yapı kendiliğinden oluşmuştur.

Madde sayıları ve boyutları gittikçe azalan ölçek yapıları doğrulayıcı faktör analizine tabi tutularak uyum ve hata indeksleri açısından karşılaştırılarak incelenmiştir. Buna göre NFI, NNFI ve CFI uyum indeksleri açısından yapılar kabul edilebilir düzeyde saptanmış, 5x5'den başlamak üzere, nöron sayısı $6 \times 6$ ve 7x7 üzerinden haritalandığında, NNFI ve CFI indeks değerleri keskin olmayan, küçük artışlar göstermiştir. GFI ve AGFI indeks değerleri ise nöron sayısı arttıkça model uyumlarında gittikçe yükselme gözlenmiştir. Ancak RMSEA hata indeksi ile $X_{M}{ }^{2} / s d$ uyum oranı $4 \times 4$ ile iki faktörde görünen yapıdan 5x5 ile tekrar üç faktöre çıkması değerlerinde olumsuz açıdan gerileme gözlenmiş 6x6 ile faktör yapısının azalması ile tekrar yapının uyum oranı artmış ve nihayetinde 7x7 üzerinden yapılan haritalamada 5 maddeli tek faktörlü yapıda en iyi değerler gözlenmiştir. Tezbaşaran (2016) tarafindan yapılan çalışmada, nöron sayısındaki artış sonucunda ölçek yapısına ait uyum ve hata indekslerinin daha iyi değerler aldığı belirtilmektedir.

Nöron sayısı arttıkça madde ve faktör sayısı azalan ölçek yapılarının farklı gruplar yöntemi ile yap1 geçerlikleri incelenmiştir. Sigara içen ve içmeyen olarak tanımlanan farklı grupların 6 farklı ölçek puanlarına göre, hepsinde sigara kullananların sigaraya ilişkin tutum puanları ortalamaları yüksek, kullanmayanların ise düşüktür. Ayrıca gruplar arası ortalama farkının istatistiksel olarak anlamlı 
olması, ortaya çıkan ölçeklerin başka bir açıdan yapı geçerliği kanıtını sağladıkları anlamına gelmektedir. Özellikle madde sayısı 5 olan tek boyutlu yapıda da bu durumun saptanmış olması, madde sayısının azalmasına rağmen istenen yapıyı ölçmedeki yeterliğini ortaya koyması açısından önemlidir.

$\mathrm{Bu}$ araştırmada, ölçülen yapının ölçek maddelerinin kapsamı ve toplanan verilerin farklılaşması nedeni ile yapı geçerliği yöntemi olarak kullanılacak KDH modeli için, başlangıçta sabit bir nöron sayısı belirlemenin mümkün olmadığı ortaya çıkmıştır. Bununla birlikte araştırma sonucu olarak, kaç adet nöron kullanılacağına ilişkin ölçüt miktar yerine, bir kural önerilmektedir: Ölçeğin maddeleri tek nöronda toplanıncaya, diğer bir deyişle, yapı tek faktöre indirgeninceye kadar nöron sayısı artırılabilir. Ancak bu kuralı uygularken ortaya çıkan boyutların adlandırılması ve denemelik ölçek oluşturulurken seçilen kuramsal tutum tanımı ve boyutları üzerinden karşılaştırılarak desteklenmesi de önerilmektedir.

KDH denetimsiz öğrenme yöntemine sahiptir. Bir başka deyişle çıtının doğru olup olmadığını belirleyecek bir iç denetimi yoktur. Ölçme araçlarının yapı geçerliğinde sonuçların yapı ile bağlamsal ilgileri oldukça önemlidir. Bu nedenle önceden yapısal boyutları kuramsal ve işevuruk olarak daha belirgin bir ölçme aracı örneğin bir bilişsel testin KDH sonuçları, dış denetim yolu ile incelenmesi ileriki araştırmalar için önerilebir.

KDH yönteminin denemelik ölçekten nihai ölçeğe madde seçmek için bazı avantajları olduğu söylenebilir. KDH aynı zamanda çok boyutlu bir yapıya sahip olan veri setinin boyut sayısını indirgeyerek, genellikle iki boyutlu bir haritada görselleştirir (Kohonen,1990). Öncelikle bu tekniğin en önemli avantajlarından biridir. Çünkü yapılar çok boyutlu ise maddeleri boyutları üzerinden görselleştirmek mümkün olmamaktadır. Ayrıca iki boyutlu çıktı haritasında doğrusal ilişkilerin yanı sıra, doğrusal olmayan ilişkileri üzerinden de maddelerin boyutlandırılmasına imkan vermektedir. KDH modeli kullanımının, parametrik istatistiksel yöntemlerin aksine, değişkenler üzerinde her hangi bir sayıltısı yoktur. Ayrıca tutumların tek boyutluluk sayıltısını karşılayabilecek şekilde maddelerin tek boyuta indirgenebilmesini sağlar. KDH yöntemi bir araştırmacının temel aldığ kurama göre geliştirdiği test ya da ölçek maddelerinin, ölçülen yapıyı ortaya koyabilmesinde, önemli bir kanıt elde etme yolu olarak düşünülebilir.

Bir başka açıdan incelendiğinde, KDH'nın yapı geçerliğinde yöntem olarak kullanılmasının bazı dezavantajlar bulunmaktadır. KDH için gerekli başlangıç parametrelerinin belirlenmesinde güçlükler vardır ve her farklı parametre değerleri farklı sonuçlar verecektir (Taşkın ve Emel, 2010). Ayrıca bu yöntemin bir diğer sınırlılı̆̆ ise, aynı veriler üzerinden ă̆ her çalıştırıldığında farklı çıktı haritalarının gözlenebilme olasılığıdır. Çünkü KDH modelinde kullanılan yarışmacı öğrenme kuralı gereği, McClelland (2015), başlangıçta ağırlık değerleri ve girdilerin sırası rasgele belirlendiğini ve bunun da, tekrarda, farklı gruplandırmalara neden olabileceğini belirtir. KDH çıktı haritası için doğru sayıda satır ve sütun nöron sayısını belirlemek zordur çünkü, bu karar bir çok deneme-yanılma sürecini gerektirmektedir (Matignon, 2007; Callica, 2011).

Fritzke (1994), nöron sayısını artırma işlemi yapan yeni bir kendini düzenleyen ağ temelli genişleyen hücre yapısı (GHY) algoritması önermiştir. Bu artırma, istenen performans ölçütü sağlanıncaya kadar ya da istenen ağ büyüklüğ̈̈ne ulaşıncaya kadar, işleme devam edilebileceğini belirtir (Fritzke 1995). Aynı zamanda Kohonen (2013), Fritzke'nin çalışmasına atıf yaparak önerilen yeni KDH versiyonunda 1zgara yapısı ve nöron sayısının hareketli olarak belirlenebileceğini belirtir. Yine Alahakoon, Halgamuge ve Srinivasan (2000) tarafindan önerilen ve dinamik yapıda bir KDH olan Genişleyen kendini düzenleyen haritalama $(\mathrm{GKDH})$ modelinin bilgiyi keşfetmede büyük avantajlar sağladığını belirtilmektedir. $\mathrm{Bu}$ modellerin ölçeklerin yap1 geçerliğinde kullanılabilirliğine dair çalışmalar yapılabilir. Ayrıca KDH modeli aynı veriler üzerinde tekrarlandığında, farklı haritalamanın ortaya çıkması olasılığı yüzünden çıkan yapıların kararlılık düzeyinin incelenmesi, ayrı bir çalışma konusu olabileceği düşünülmektedir.

KDH modelinde nöron sayısı dışında, nöron serisinin boyutluluğu, nöronların birbiri ile komşuluk ilişkisi/şekli, komşuluğun daralma planı ve ağın öğrenme hızı gibi parametreler mevcuttur. $\mathrm{Bu}$ parametrelerin her birinin ve kombinasyonlarının, yapı geçerliği çalışması üzerindeki etkilerinin 
incelenmesi, ileriki çalışmalar için önerilebilir. Bu çalışmalarda, ölçülen değişkeni etkileyebileceği düşünülen değişkenler açısından, araştırma grubunun frekans dağılım dengesi göz önünde tutulmalıdir.

\section{KAYNAKÇA}

Alahakoon, D., Halgamuge, S.K. \& Srinivasan, B. (2000). Dynamic self-organizing maps with controlled Growth for knowledge discovery. IEEE Transactions on Neural Networks. 11(3), 601-614.

Anastasi, A. (1988). Psychological Testing. New York: Macmillan Publishing Company.

Bogdan, R. C. \& Biklen, S. K. (1998). Qualitative research for education. Boston: Allyn and Bacon.

Callica, R. (2011). Customer segmentation and clustering using SAS enterprise miner. USA: North Carolina Institute.

Cheng, B. \& Titterington, D.M. (1994). Neural Networks: A review from a statistical perspective. Statistical Science. 9(1), 2-54.

Cohen, R.J., Montague, P., Nathanson L.S. \& Swerdlik, M.E. (1988). Psychological testing. Mountain View: Mayfield Publishing Company.

DeVellis, R.F. (2003). Scale Developmert Theory and Applications. Thousand Oaks: SAGE Publicatians.

Elmes, D. G., Kantowitz, B. H. \& Roediger III, H. L. (1992). Research methods in psychology. St. Paul: West Publishing Company.

Feldman, R.S. (1997). Essentials of understanding psychology. New York: The McGraw-Hill Companies, Inc.

Fritzke, B. (1994). Growing cell structure: A self organizing network for supervised and un-supervised learning. Neural Networks. 7.1441-1460.

Fritzke, B. (1995). Growing grid - a self-organizing network with constant neighborhood range and adaptation strength. Neural Processing Letters. 2(5), 9-13.

Holtzman, S. \& Vezzu, S. (2011). Confirmatory factor analysis and structural equation modeling of noncognitive assessments using PROC CALIS. Retrieved from www.lexjansen.com/nesug11/sa/sa07.pdf

Jain, A.K, Mao, J. \& Mohiuddin, K.M. (1996). Artificial neural network. Retrieved from http://www.cogsci.ucsd.edu/ ajyu/Teaching/Cogs202_sp12/Readings/jain_ann96.pdf

Johnson, R.A. \& Wichern, D.W. (1982). Applied multivariate statistical analysis. London: Prentice-Hall International, Inc.

Karasar, N. (1998). Bilimsel araştırma yöntemi. Ankara: Nobel Yayın Dağıtım.

Kline, R.B. (2005). Principles and practice of structural equation modeling. New York: The Guilford Press.

Kohonen, T. (1982). Self-Organized Formation of Topologically Correct Future Maps. Biological Cybernetics, $43,59-69$.

Kohonen, T. (1990). The Self-Organizing Map. Proceedings of The IEEE. 78(9), 1464-1480.

Kohonen, T. (2013). Essentials of self-organizing map. Neural Networks. 37, 52-65.

Matignon, R. (2007). Data mining using SAS enterprise miner. New Jersey: John Wiley \& Sons.

McClelland, J.L. (2015). Explorations in parallel distributed processing: A handbook of models, programs, and exercises. Retrieved from web.stanford.edu/group/pdplab/pdphandbook/handbookch7.html

Murphy, K.R. ve Davidshofer, C.O. (2001). Psychological Testing Principles and Applications. New Jersey: Prentice Hall Inc.

Taşkın, Ç. ve Emel, G.G. (2010). Veri madenciliğinde kümeleme yaklaşımları ve kohonen ağları ile perakendecilik sektöründe bir uygulama. Süleyman Demirel Üniversitesi İktisari ve İdari Bilimler Fakültesi Dergisi. 15(3), 395-409.

Tezbaşaran, A. A. ve Kelecioğlu, H. (2004). Madde-ölçek korelasyonlarına, alt-üst grup ortalamalarına ve aşamalı tepki modeline göre geliştirilen sigaraya ilişkin tutum ölçeğinin madde ve ölçek özelliklerinin incelenmesi. XIII. Ulusal Eğitim Bilimleri Kurultayl, Malatya, Türkiye

Tezbaşaran, E. (2016). Temel bileşenler analizi ve yapay sinir ă̆ modellerinin ölçek geliştirme sürecinde kullanılabilirliğinin incelenmesi. (Yayınlanmamış Doktora tezi, Mersin Üniversitesi, Eğitimde Ölçme ve Değerlendirme Anabilim Dali, Mersin).

Ullman, J. B. (2001). Structural equation modeling. In B.G. Tabachnick and L.S. Fidell (Eds.), Using Multivariate Statistics (p. 653-771). Boston: Allyn § Bacon.

Vesanto, J., Himberg, J., Alhoniemi, E. \& Panhankangas, J. (2000, February). Self-organizing map in matlab: the SOM toolbox. Updated version of the paper published in Proceedings of the Matlab-DSP 1999 Conference. Retrieved from http://lib.tkk.fi/Diss/2002/isbn951226093X/article2.pdf

Westerlund, M. L. (2005). Classification with Kohonen self-organizing maps. Retrieved from www.hi.is/ benedikt/Courses/Mia_report2.pdf 


\section{EXTENDED ABSTRACT}

\section{Introduction}

Construct validity is an important psychometric property in terms of an evidence for the validity of a scale developing to measure psychometric variables. Construct validity of a scale is determined by evidences getting from various methods. One of these methods is factor analysis that detects the factor construct of a scale.

The aim of the research is to find out /to determine what the number of neuron (grid size) should be used in self-organizing mapping when it is used for construct validity of a Likert type scale instead of the factor analysis done with the technique of the principal component analysis used in the construct validity studies in practice. Self-organizing mapping which is an artificial neural network model developed by Kohonen is used for classification and data reduction. Network outputs can be visualized in a two dimensional map. This network detects the input features and gives a map of characteristics of the inputs on a plane.

There are three research questions to investigate the self-organizing mapping as a method for construct validity of Attitudes Towards Smoking Scale:

1. What are the constructs of the scale obtained from self-organizing mapping using different grid size?

2. What are the fit end error indexes of the different constructs of the scale obtained from selforganizing mapping using different grid size according to confirmatory factor analysis?

3. What is the construct validity of the different constructs of the scale obtained from selforganizing mapping using different grid size according to evidence from distinct groups method?

\section{Method}

540 individuals aged between $18-56$ voluntarily participated in this research as study group. Nearly $60 \%$ of the participants were university students and $40 \%$ of them was university graduate. Attitudes Towards Smoking Scale preparing by Tezbaşaran and Kelecioğlu (2004) was used to investigate the construct validity. The 41-item scale is a Likert type scale consisting of 19 positive and 22 negative attitude expressions.

As a first step, factor constructs of the scale were analyzed with self-organizing mapping using $2 \times 2$, $3 \times 3,4 \times 4,5 \times 5,6 \times 6,7 \times 7$ grid sizes respectively. Each output of network is visualized on two dimensional hexagonal grid. Then, the scale constructs obtained from 6 different grid size were analyzed with confirmatory factor analysis. Results of the analysis that give fit end error indexes of different construct of the scale obtained from different grid size were compared. On the other hand, independent samples t-test was used to explore the construct validities of 6 different scale obtained in the way of distinct groups method. Distinct groups were defined as smokers and non-smokers. It was analyzed repeatedly for each scale construct to find whether there is a statistically significant difference between their means of scale scores.

\section{Results and Discussion}

Since all items are in one neuron, at the beginning $2 \times 2$ grid size self-organizing mapping having outputs on the 4-neuron map was used to get the scale construct. In two-dimensional mapping, the items of Attitudes Towards Smoking Scale fall apart in 4 neurons. As one item of the scale is in a different neuron, it was excluded and 3 factors with 40 items were observed. In two dimensional mapping, a construct with 3 factors and 37 items was emerged on the condition that the number of neuron was $3 \times 3$. When the number of neuron is raised to 16 on $4 \times 4$, the total item number lowers to 26 and factor number to 2 . When the number of neuron is 25 on $5 \times 5$, the factor construct is again 3 and the number of items lowers to 19 since the items are separating more in terms of their 
similarities and differences. When the total number of neuron in the map raises 36 on $6 \times 6$, it was observed that the number of factor lowers to 2 and of items to 11 as the items are separating much more from each other. It was seen that a construct with 5 items and 1 dimension emerges when the separation of the items is investigated on a map with $7 \times 7$. At this point, the neuron rise was stopped as each of the items fall apart in one neuron whenever the number is raised.

The constructs of the scale whose item and factor numbers were continuously decreasing, were investigated by using confirmatory factor analysis and comparing in terms of the fit and error indexes. As a consequence, by lowering the item and factor numbers with increasing the grid size through $7 \times 7$, the fitting of the construct raised and finally on the mapping done on $7 \times 7$, the construct with 5 items in one factor had the best values.

On the other hand, the attitude the mean scores of smokers are high whereas the mean scores of nonsmokers are low, and the difference between them is statistically meaningful. This is also an evidence that the scales have the construct validity. It is important to see the efficiency for measuring the construct in spite of lowering the number of items, particularly in one dimension with 5 items.

Although differentiation of scale items of different psychological construct measured and the differentiation of the gathered data hinder giving an exact neuron number of self-organizing mapping to be used as a construct validity method, a rule can be given as a result of this research: Related to making decision on the number of neuron to be used, it can be increased until the related items of a scale is observed in one neuron, in other words, until a construct with one factor is observed. In addition to this rule, it is recommended to analyze the revealed construct with respect to related attitude variable contextually. 